\title{
The effectiveness and prognostic factors of radioactive iodine-125 seed implantation for the treatment of cervical lymph node recurrence of esophageal squamous cell carcinoma after external beam radiation therapy
}

\author{
Yuwei Zhang, MA!, Zezhou Liu, BA², Yansong Liang, MA², Enli Chen, BA!, Hongtao Zhang, MD², Zhen Gao, MA², \\ Juan Wang, MD2 \\ 'Graduate School of Hebei Medical University, Shijiazhuang, Hebei, China, ${ }^{2}$ Department of Oncology, Hebei General Hospital \\ Shijiazhuang, Hebei, China
}

\begin{abstract}
Purpose: To analyze factors influencing the efficacy of ${ }^{125} \mathrm{I}$ seed implantation in the treatment of in-field cervical lymph node recurrence of esophageal squamous cell carcinoma (ESCC) after external beam radiation therapy.

Material and methods: We conducted a retrospective review of 36 patients with in-field cervical metastatic lymph nodes recurrence of esophageal squamous cell carcinoma (CML-ESCC) after external beam radiation therapy treatment, who underwent ${ }^{125}$ I seed implantation in our department from 2013 to 2019. Previous cumulative external irradiation dose ranged from 20 to $66 \mathrm{~Gy}$ (median, $60 \mathrm{~Gy}$ ). The post-implant efficacy was evaluated by response evaluation criteria in solid tumors (RECIST) version 1.1, and an adverse event was evaluated by the Radiation Therapy Oncology Group (RTOG)/European Organization for Research and Treatment of Cancer Late Radiation Morbidity Score (EORTC). COX proportional hazards model was used to analyze risk factors affecting effectiveness.

Results: Among 36 patients, 31 patients (86.1\%) received fluorouracil-based chemotherapy (1-6 cycles) after ${ }^{125}$ I seed implantation. Local control rates at 3, 6, 12, and 24 months after implantation were 51\%, 30\%, 30\%, and 18\%, respectively, with a median of 9 months (95\% CI: 6.106-11.894); survival rates after 3, 6, 12, and 24 months were 55\%, $41 \%, 22 \%$, and $22 \%$, respectively, with a median of 8 months (95\% CI: 5.753-10.247). Multivariate analysis showed that $\mathrm{D}_{90}$ and short-term efficacy were independent factors related to local control and survival rate $(p=0.005,<0.001,0.010$, $<0.001)$. There were 2 cases (5.6\%) with grade 1 skin toxicity, 1 case $(2.8 \%)$ with grade 4 skin toxicity, 3 cases $(8.3 \%)$ with grade 1 mucosal ulcer, and 3 cases $(8.3 \%)$ with grade 1 xerostomia.

Conclusions: ${ }^{125}$ I seed implantation as an effective salvage treatment shows definite efficacy and safety for patients with in-field cervical lymph node recurrence of ESCC after external beam radiation therapy.

Key words: cervical lymph node, esophageal squamous cell cancer, ${ }^{125}$ I seed implantation.

\section{Purpose}

Esophageal cancer (EC) is the eighth most common cancer worldwide [1], with esophageal squamous cell cancer (ESCC) accounting for nearly $90 \%$ of all cases of EC [2]. In China, ESCC ranks as the third most common malignancy and the fourth most common cause of cancer-related death [3]. Most patients diagnosed with ESCC have advanced disease, and long-term survival rates are still far from satisfactory. Although advances in medical treatment have improved survival rate of patients, locoregional lymph node recurrence is still the predominant pattern of treatment failure in ESCC $[4,5,6]$. If lymph node recurrence is treated effectively, long-term survival may be ensured [7]. Nevertheless, the treatment of ESCC with lymph node recurrence is always challenging due to previous treatments (lymphadenectomy, radiotherapy, and chemotherapy, etc.), which limits the remaining options for subsequent salvage treatment. Repeated radiation therapy has been applied; however, the target dose is 
generally limited by the tolerance of adjacent normal tissue. The overall response is far from satisfactory because of severe and even life-threatening treatment-related adverse reactions, limiting its application in clinical practice [8]. Taken together, effective treatment of recurrent cervical lymph node of ESCC after radiation therapy remains a challenge in cancer treatment.

Interstitial implantation of radioactive ${ }^{125} \mathrm{I}$ seeds is a minimally invasive, safe, and effective treatment for malignant tumors, and plays a pivotal role in salvage therapy of numerous neoplasms, both in the local control of primary tumor as well as in the control of metastatic disease. However, there are few reports on the efficacy of external beam radiation therapy with ${ }^{125} \mathrm{I}$ seed brachytherapy in in-field cervical metastatic lymph nodes recurrence of ESCC (CML-ESCC). Our research retrospectively evaluated the clinical outcome of ${ }^{125} \mathrm{I}$ seed implantation for in-field CML-ESCC, and analyzed related factors influencing efficacy.

\section{Material and methods}

\section{Clinical information}

We retrospectively analyzed the data of 36 patients with in-field CML-ESCC after radiation therapy, who received computed tomography (CT)-guided radioactive ${ }^{125}$ I seed implantation from January 2013 to March 2019.

Eligibility criteria were as follows: 1 . Solitary pathologically confirmed in-field cervical lymph node recurrence, with suitable puncture access; 2 . Maximum diameter of tumor $\leq 7 \mathrm{~cm}$; 3 . Inability to tolerate surgery or refusal of surgical treatment, or with limited chemotherapy efficacy, and an informed consent signed by the patient or legal guardian; 4 . No dysfunction of important organs, including heart, lung, kidney, etc.; 5. Karnofsky performance status (KPS) $\geq 60$, and expected survival $\geq 3$ months; 6 . 1 week before implantation, medical history, physical examination, routine hematological, and biochemical analysis, and enhanced CT examination performed. TNM staging was performed according to the Union for International Cancer Control (UICC) criteria.

Exclusion criteria involved: 1. Severe organ dysfunction; 2. Coagulation dysfunction; 3 . Poor general condition or cachexia; 4 . Less than 2 months from the end of last external radiotherapy; 5 . No CT and other imaging data at 3 months after implantation. All patients were informed about the treatment and signed the informed consent. The protocol was approved by the Ethics Committee of Hebei General Hospital.

\section{Pre-operative planning}

The patients underwent enhanced CT scan (thickness, $5 \mathrm{~mm}$ ) at 1 week before the treatment. CT images were transmitted to computer-assisted treatment planning system (Panther Brachy v5.0 TPS, Prowess Inc., USA) to evaluate the feasibility of treatment and to design preoperative planning, including assessments of gross tumor volume (GTV) and adjacent organs at risk (OARs, with esophagus, trachea, skin, and oral mucosa), clinical target volume (CTV), which was defined as a $0.5 \mathrm{~cm}$ of expansion external to GTV, angle and depth of needles, as well as distribution of seeds. The prescription dose was given according to the radiation dose received by OARs at the last external radiotherapy and the time to progression, ranging from 45 to $140 \mathrm{~Gy}$. ${ }^{125}$ I seeds, which was purchased from Shanghai Xinke Pharmaceutical Company, had a length of $4.5 \mathrm{~mm}$ and diameter of $0.8 \mathrm{~mm}$ (activity: 0.3-0.8 mCi; half-life: 59.4 days). These parameters were specified in the TPS to define CTV with the aim of covering $\geq 90 \%$ of CTV by the prescription dose.

\section{Seed implantation technique}

Enhanced CT was applied to locate tumor target and to guide ${ }^{125} \mathrm{I}$ seeds implantation. $18 \mathrm{G}$ implantation needles were used for the implantation of ${ }^{125}$ I seeds. Preimplantation computerized treatment planning was performed on treatment planning system (TPS). According to the CT images, GTV and areas at risk of subclinical disease were outlined. The planning target volume (PTV) included the entire GTV with a margin of $5 \mathrm{~mm}$. The $\mathrm{D}_{90}$ was calculated with TPS.

After fasting for 2 hours, the patients were administered with sedatives and local anesthesia before the implantation. The skin at the needle entry site was prepared and draped in a sterile fashion. Based on the preplanning, the $18 \mathrm{G}$ implantation needles were placed $1.0 \mathrm{~cm}$ apart in a parallel array within the PTV. Cautions were taken to avoid puncturing of the large blood vessels, neural structures, and vital organs. The depth and angle of implanted needles were monitored by repeated CT imaging and adjusted during procedures when necessary. After placing the needles, ${ }^{125}$ I seeds were released every $0.5-1 \mathrm{~cm}$ apart, with gradual withdrawal of the needles. The seeds were loaded utilizing a modified peripheral method, in which fewer central seeds and more peripheral seeds were implanted according to the pre-planning. Puncture sites were bandaged and compressed for hemostasis after the implantation.

\section{Post-implant verification}

CT scan was performed immediately after implantation, and images were transmitted to TPS for dose verification. Dose parameters including $\mathrm{D}_{90}$ and $\mathrm{D}_{100}$ (the dose delivered to $90 \%$ and $100 \%$ CTV, respectively) were calculated to evaluate the dose distribution.

\section{Post-implant medication}

The patients received a course of antibiotics and hemostasis to prevent the occurrence of infection and bleeding after surgery. Thirty-one patients $(86.1 \%)$ received fluorouracil-based chemotherapy (1-6 cycles), and 5 patients $(13.9 \%)$ declined chemotherapy because of poor constitution or intolerance to toxicity caused by chemotherapy.

\section{Follow-up}

The efficacy was evaluated at 3 months after implantation, every 3 months within 2 years, and every 6 months 
thereafter. The re-examination included routine blood test, biochemical examination, tumor marker examination, and enhanced CT or PET-CT.

\section{Outcome measures}

\section{Local control rate (LCR) and survival rate}

After implantation of ${ }^{125} \mathrm{I}$ seeds, CT was performed at each follow-up to determine the tumor size, and the survival from the day of implantation was recorded. Treatment response was assessed as per RECIST 1.1 [9], complete response (CR, disappearance of target lesion), partial response (PR, reduction of target lesion volume by at least $30 \%$ from baseline), progressive disease (PD, increase in target lesion volume by at least $20 \%$ ), and stable disease (SD, between PR and PD) (Figure 1). Local control was defined as $\mathrm{CR}+\mathrm{PR}+\mathrm{SD}[\mathrm{LCR}=(\mathrm{CR}+\mathrm{PR}+\mathrm{SD}) /$ total], and short-term ( 3 months after implantation) efficacy was divided into CR + PR and SD + PD according to RECIST 1.1

\section{Toxicity and side effects}

Adverse events were evaluated according to the Radiation Therapy Oncology Group (RTOG)/European Organization for Research and Treatment of Cancer Late Radiation Morbidity Score (EORTC) [10] at 3 months after the implantation.

\section{Prognostic factors}

Factors analyzed included age, KPS, pathological grading, cumulative dose of previous radiotherapy, previous TNM stage, lesion volume, $\mathrm{D}_{90}$, seed activity, time to progression, post-implant chemotherapy, and shortterm efficacy (three months after the implantation).

\section{Statistical analysis}

Statistical analysis were computed using SPSS version 25.0. Kaplan-Meier method was applied to calculate LCR and survival rate. The $\chi^{2}$ test was performed to analyze rates. Log-rank test and COX proportional hazards model were performed for univariate and multivariate analysis, respectively. $P<0.05$ was considered statistically significant.

\section{Results}

\section{Patients characteristics and seed implantation}

In this study, there were 32 men $(88.9 \%)$ and 4 women (11.1\%), aged from 47 to 77 years (median, 63.17 years), with KPS scores from 60 to 90 (median, 80), and previous cumulative radiation doses from 20 Gy to 66 Gy (median, $60 \mathrm{~Gy}$ ). Local recurrence was confirmed by a pathological examination. According to the pathological grading, 21 cases $(58.3 \%)$ had low-grade and 15 cases $(41.7 \%)$ presented moderate- or high-grade.

The tumor lesion volume was 7 to $66 \mathrm{~cm}^{3}$ (median, $21.20 \mathrm{~cm}^{3}$ ), time to progression was 2 to 50.7 months (median, 8.6 months), seed activity was 0.3 to $0.8 \mathrm{mCi}$ (median, $0.5 \mathrm{mCi}$ ), number of implanted seeds was 14 to 100 (median, 37.5), and post-implant $D_{90}$ was 47 to 151 Gy (median, $104 \mathrm{~Gy}$ ). In addition, $\mathrm{D}_{2 \mathrm{cc}}$ of skin was 2.22 to 139.41 Gy (median, 32.96 Gy).

\section{Treatment outcome}

The patients were followed up for 3 to 29 months (median, 17 months). Evaluations of short-term efficacy revealed CR in 2 patients, PR in 18 patients, SD in 6 patients, and PD in 10 patients. The 3-, 6-, 12-, and 24-month LCR was $51 \%, 30 \%, 30 \%$, and $18 \%$, respectively, with a median of 9 months (95\% CI: 6.106-11.894). The median survival time was 8 months (95\% CI: 5.753-10.247), and $3-, 6-, 12-$, and 24 -month survival rates were $55 \%, 41 \%$, $22 \%$, and $22 \%$, respectively. At the last follow-up, 11 patients were alive with no systemic recurrence, out of which $45.5 \%$ were in complete remission. The other 25 patients died from multiple metastases at $3 \sim 26$ months after the implantation. In terms of side effects, there were 2 cases $(5.6 \%)$ with grade 1 skin toxicity, 1 case $(2.8 \%)$ with grade 4 skin toxicity, 3 cases $(8.3 \%)$ with grade 1 mucosal ulcer, and 3 cases (8.3\%) with grade 1 xerostomia. No seed migration was observed.

\section{Prognostic factors}

Univariate analysis showed that $\mathrm{M} 0$ stage, $\mathrm{D}_{90}$ $\geq 110 \mathrm{~Gy}$, time to progression, and short-term efficacy (CR or PR) were correlated with higher survival rates $(p=0.006,0.013,0.007$, and $<0.001$, respectively). Multi-

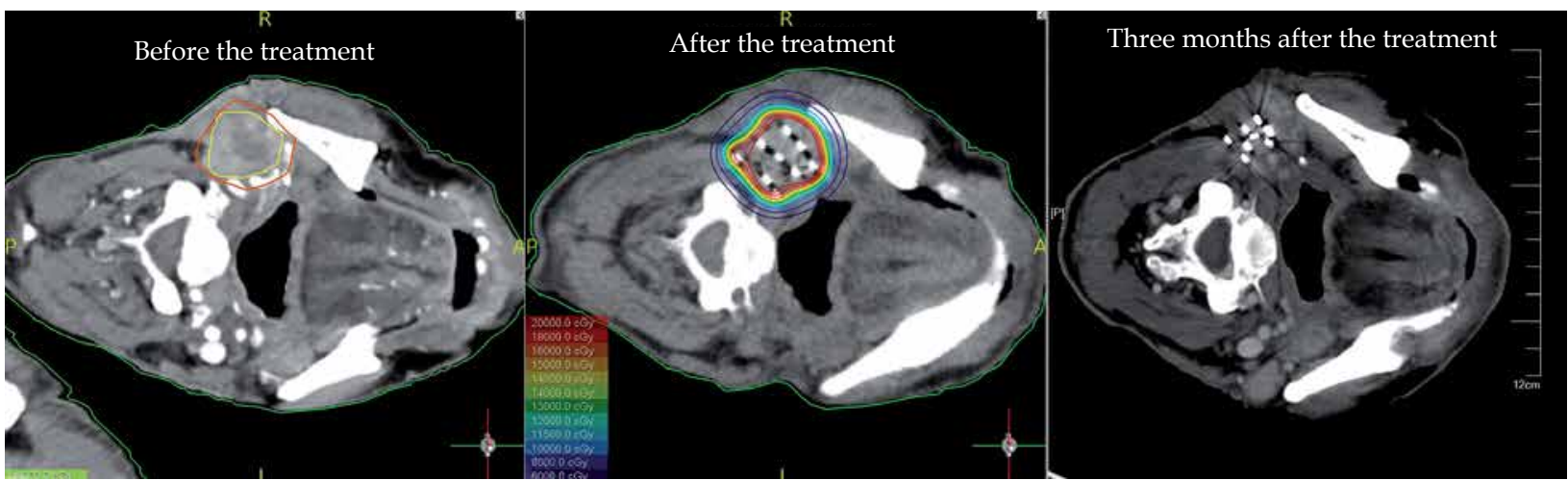

Fig. 1. ${ }^{125}$ I implantation for a patient with cervical lymph node recurrence of esophageal squamous cell carcinoma after external beam radiation therapy. Local efficacy was evaluated as complete response (CR) 
variate analysis revealed that independent factors of survival rate included $D_{90}$ and short-term efficacy (CR or PR) ( $p=0.010,<0.001$, as shown in Table 1$)$. In addition, univariate analysis indicated factors related to LCR included tumor volume, $\mathrm{D}_{90}$, pathological grading, and short-term efficacy (CR or PR) ( $p=0.019,0.004,0.019$, $<0.001$, respectively). Multivariate analysis showed that $\mathrm{D}_{90}$ and short-term efficacy were the independent influencing factors of LCR $(p=0.005,<0.001$, respectively, as shown in Table 2). In this study, the subgroup analysis of dose demonstrated that $\mathrm{D}_{90} \geq 110$ Gy was associated with significantly better local control and survival rate than $\mathrm{D}_{90}<110$ Gy (median, 10 vs. 6 months, $p=0.019 ; 18$ vs. 7 months, $p=0.013$ ) (Figure 2).

\section{Discussion}

Recently, radioactive ${ }^{125}$ I seed implantation has been increasingly employed in the treatment of tumors due to its efficacy, safety, feasibility, and minimally invasive nature of therapy [11,12]. ${ }^{125}$ I seeds release low-dose-rate $X$ - and $\gamma$-ray continuously, and deliver a dose of 160 to $180 \mathrm{~Gy}$ in the tumor target during a half-life period. The characteristic of ${ }^{125}$ I seed helps to suppress the proliferation and repair of cancer cells, while the adjacent normal tissues would not receive $\geq 25 \%$ of the dose delivered to tumor target [13]. Theoretically, ${ }^{125}$ I seed implantation is a potential treatment option for recurrent lesions after radiotherapy [14,15,16]. Park et al. [17] treated 35 patients with positive surgical margin or insufficient resection of recurrent advanced squamous cell carcinoma (SCC) of the head and neck by ${ }^{125}$ I seed implantation, and the results showed that the 5 -year disease-free survival rate was $41 \%$. Chen et al. [18] reported 24 patients with recurrent head and neck tumors, who underwent ${ }^{125}$ I seed implantation, and the results indicated a 2-year survival rate of $29 \%$. It was suggested that radioactive ${ }^{125} \mathrm{I}$ seed implantation was an effective method for the treatment of recurrent head and neck tumors. However, the research on the efficacy of radioactive ${ }^{125} \mathrm{I}$ seed implantation in the treatment of head and neck cancers included multiple types of tumors, along with other confounding factors, such as multiple tumor sites and imaging guidance. In this study, only ESCC patients were included, and CT was merely used as an imaging guidance due to the fact that the operation was usually blocked by the bone with deep tumor position, and it was not compatible between the ultrasound and treating planning system regarding dose verification. In addition, it could be more convenient and accurate to recognize the margin of tumor with an enhanced CT, which could achieve the same effect as ultrasound and MRI. The influencing factors of efficacy of ${ }^{125} \mathrm{I}$ seeds in the treatment for in-field CML-ESCC after radiotherapy were analyzed, so as to provide references for future dose-escalation trial and population selection.

Our study showed that the LCRs at 3, 6, 12, and 24 months after the implantation were $51 \%, 30 \%, 30 \%$, and $18 \%$, respectively (median, 9 months), and the survival rates were $55 \%, 41 \%, 22 \%$, and $22 \%$, respectively (median, 8 months). Lin et al. [19] reported 19 patients (32 lesions) with CLM-ESCC after multimodal therapy treated by ${ }^{125} \mathrm{I}$ seed, and results showed 12 - and 24 -month survival rates of $31.6 \%$ and $10.5 \%$, respectively. The survival rate of patients in the present study was higher than that of Lin et al. Considering the clinical baseline condition of patients, Lin et al. included patients who relapsed after multiple treatments (including surgery, chemotherapy, radiotherapy, etc.) with multiple lesions. However, in our study, no patients presented multiple lesions, and the tumor burden was relatively small. Thirty-one patients received chemotherapy after the implantation; this indicated that compared with a monotherapy, seeds combined with chemotherapy had the tendency to improve the patients' survival rates. Ji et al. [20] reported on 101 patients with recurrent head and neck cancer after radiotherapy, who were followed up for 2.9 to 73.2 months (median, 12.2 months). Their results revealed that a 12-month LCR was $40.6 \%$; a 1-, 3-, and 5-year survival rates were 54.3\%, 15.5\%, and $54.3 \%$, respectively. The large differences between our results and that by Ji et al. might be attributed to different pathological types of tumor. Ji et al. reported on 75 patients with SCC (12-month LCR of 29.6\%) and 26 patients with non-squamous cell carcinoma (non-SCC, 75.3\%). It can be assumed that ${ }^{125} \mathrm{I}$ seeds may have a better effect on nonSCC patients. Moreover, the improvement of local efficacy would increase the survival rate of patients. Takiar et al. [21] reported on 206 patients with head and neck cancer treated by intensity-modulated radiation therapy, with 173 SCC patients and 33 non-SCC patients. The results showed that a 5-year LCR, progression-free survival, and overall survival were significantly lower in the SCC group than in the non-SCC group of patients. Their outcomes were consistent with survival rate in our study, which was lower than that reported by Ji et al. Furthermore, COX proportional hazards model showed that $\mathrm{D}_{90}$ and short-term efficacy were independent prognostic factors affecting LCR and survival rate. Long-term LCR and survival rate were higher for $\mathrm{D}_{90} \geq 110 \mathrm{~Gy}$, and short-term efficacy reaching CR or PR, which was in accordance with the results of Lin et al. [19] and Ji et al. [20]. The dose received by target area was higher with a larger $D_{90}$, and the radiation led single- or double-strand DNA of tumor cells to break thoroughly, thus resulting in apoptosis of tumor cells, which could more effectively achieve local control of tumor and improve the survival rate of patients. In conclusion, the results of this study provide important references for the selection of prescription dose.

The RTOG-9610 study included 86 patients with recurrent SCC of head and neck or secondary tumor in the radiotherapy field, who received external radiotherapy and concurrent chemotherapy (60 Gy/4 fx). The incidence of grade 4 and 5 severe acute radiation reactions was $17.7 \%$ and $7.6 \%$, respectively, whereas the incidence of grade 3-4 late toxicity was $3.4 \%$ and $3.0 \%$, respectively [22]. Langer et al. [23] treated 105 patients with recurrent SCC of the head and neck by concurrent chemoradiotherapy, and the results indicated that the incidence of grade 4 and above adverse reactions was $28 \%$. Because of the physical characteristics of ${ }^{125} \mathrm{I}$ seed, the dose received by peripheral tissues was declined rapidly, thereby producing fewer side effects. In our study, there were 2 cases $(5.6 \%)$ of grade 1 skin toxicity, 1 case $(2.8 \%)$ with grade 4 skin toxicity, 3 cases $(8.3 \%)$ with grade 1 mucosal ulcer, and 
Table 1. Univariate and multivariate analysis of factors for survival

\begin{tabular}{|c|c|c|c|c|c|c|c|c|c|c|c|c|}
\hline \multirow{2}{*}{\multicolumn{2}{|c|}{ Factor }} & \multirow[t]{2}{*}{$n$} & \multirow{2}{*}{$\begin{array}{c}\text { Median } \\
(\mathrm{mo})\end{array}$} & \multirow{2}{*}{$\begin{array}{c}6 \mathrm{mo} \\
(\%)\end{array}$} & \multirow{2}{*}{$\begin{array}{c}12 \mathrm{mo} \\
(\%)\end{array}$} & \multirow{2}{*}{$\begin{array}{c}18 \mathrm{mo} \\
(\%)\end{array}$} & \multirow{2}{*}{$\begin{array}{c}24 \mathrm{mo} \\
(\%)\end{array}$} & \multicolumn{3}{|c|}{ Univariate analyses } & \multicolumn{2}{|c|}{ Multivariate analyses } \\
\hline & & & & & & & & $\chi^{2}$ & $P$-value & $\mathrm{HR}$ & $95 \% \mathrm{Cl}$ & $P$-value \\
\hline \multicolumn{13}{|c|}{ Age (years) } \\
\hline$<6$ & & 11 & 18 & 73 & 55 & 0 & 0 & \multirow[t]{2}{*}{1.310} & \multirow[t]{2}{*}{0.252} & \multirow[t]{2}{*}{0.611} & & \\
\hline$\geq 6$ & & 25 & 6 & 48 & 35 & 22 & 22 & & & & & \\
\hline \multicolumn{13}{|l|}{ KPS } \\
\hline$\leq 7$ & & 13 & 8 & 53 & 35 & 35 & 35 & \multirow[t]{3}{*}{1.939} & \multirow[t]{3}{*}{0.379} & \multirow[t]{3}{*}{0.889} & & \\
\hline $70-$ & & 12 & 5 & 42 & 33 & 0 & 0 & & & & & \\
\hline$>8$ & & 11 & 18 & 73 & 55 & 36 & 36 & & & & & \\
\hline \multicolumn{13}{|c|}{ Seed activity } \\
\hline$<0$ & & 17 & 9 & 65 & 47 & 24 & 24 & \multirow[t]{2}{*}{0.347} & \multirow[t]{2}{*}{0.556} & \multirow[t]{2}{*}{1.244} & & \\
\hline$\geq 0$ & & 19 & 7 & 47 & 35 & 19 & 19 & & & & & \\
\hline Prima & y tumo & & & & & & & & & & & \\
\hline T & $\mathrm{T} 1$ & 18 & 8 & 56 & 39 & 26 & 26 & 0.435 & 0.804 & 1.009 & & \\
\hline & $\mathrm{T} 2$ & 8 & 9 & 63 & 47 & 28 & 28 & & & & & \\
\hline & T3 & 10 & 7 & 50 & 40 & 0 & 0 & & & & & \\
\hline$N$ & NO & 9 & 8 & 56 & 44 & 22 & 22 & 1.865 & 0.394 & 1.193 & & \\
\hline & N1 & 8 & 26 & 74 & 59 & 59 & 59 & & & & & \\
\hline & N2 & 19 & 6 & 47 & 32 & 12 & 12 & & & & & \\
\hline$M$ & MO & 27 & 14 & 67 & 51 & 27 & 27 & 7.471 & 0.006 & 2.976 & & 0.187 \\
\hline & M1 & 9 & 5 & 22 & 11 & 0 & 0 & & & & & \\
\hline Patho & ogical & & & & & & & & & & & \\
\hline Lon & & 21 & 8 & 57 & 33 & 13 & 13 & 1.218 & 0.270 & 0.648 & & \\
\hline $\begin{array}{l}\text { Mo } \\
\text { or } 1\end{array}$ & $\begin{array}{l}\text { lerate } \\
\text { igh }\end{array}$ & 15 & 18 & 53 & 53 & 35 & 35 & & & & & \\
\hline Irradi & tion do & & & & & & & & & & & \\
\hline$\leq 5$ & & 4 & 5 & 25 & 25 & 25 & 25 & 0.634 & 0.728 & 0.739 & & \\
\hline $50-$ & & 28 & 8 & 61 & 42 & 12 & 12 & & & & & \\
\hline$>6$ & & 4 & 3 & 50 & 50 & 50 & 50 & & & & & \\
\hline Lesior & volum & & & & & & & & & & & \\
\hline$<2$ & & 11 & 14 & 76 & 46 & 46 & 46 & 2.496 & 0.114 & 2.040 & & \\
\hline$\geq 2$ & & 25 & 8 & 34 & 8 & 8 & 8 & & & & & \\
\hline $\mathrm{D}_{90}(\mathrm{C}$ & & & & & & & & & & & & \\
\hline$<11$ & & 21 & 7 & 48 & 24 & 0 & 0 & 6.147 & 0.013 & 0.330 & $1.376-$ & 0.010 \\
\hline$\geq 11$ & & 15 & 18 & 67 & 67 & 40 & 40 & & & & 10.831 & \\
\hline Post-c & perativ & nothe & apy & & & & & & & & & \\
\hline Yes & & 32 & 8 & 59 & 44 & 23 & 23 & 3.392 & 0.066 & 2.808 & & \\
\hline No & & 4 & 3 & 25 & 0 & 0 & 0 & & & & & \\
\hline Time & rom rac & ther & by to recu & rence $(n$ & & & & & & & & \\
\hline$<1$ & & 21 & 5 & 33 & 16 & 16 & 16 & 7.399 & 0.007 & 0.336 & & 0.250 \\
\hline$\geq 10$ & & 15 & 18 & 87 & 73 & 32 & 32 & & & & & \\
\hline Short & term ef & & & & & & & & & & & \\
\hline$C R$ & $P R$ & 20 & 18 & 85 & 64 & 41 & 41 & 15.627 & 0.000 & 4.435 & 0.073- & 0.000 \\
\hline SD & PD & 16 & 5 & 19 & 13 & 0 & 0 & & & & 0.459 & \\
\hline
\end{tabular}

$C l$ - confidence interval, $C R$ - complete response, $D_{90}-90 \%$ of target volume, HR - hazard ratio, KPS - Karnofsky performance status, PD - progress disease, $P R$ - partial response, $S D$ - stable disease, mo-months 
Table 2. Univariate and multivariate analysis of factors for local control

\begin{tabular}{|c|c|c|c|c|c|c|c|c|c|c|c|}
\hline \multirow[t]{2}{*}{ Factor } & \multirow[t]{2}{*}{$n$} & \multirow{2}{*}{$\begin{array}{l}\text { Median } \\
\text { (mo) }\end{array}$} & \multirow{2}{*}{$\begin{array}{c}6 \mathrm{mo} \\
(\%)\end{array}$} & \multirow{2}{*}{$\begin{array}{c}12 \mathrm{mo} \\
(\%)\end{array}$} & \multirow{2}{*}{$\begin{array}{c}18 \mathrm{mo} \\
(\%)\end{array}$} & \multirow{2}{*}{$\begin{array}{c}24 \text { mo } \\
(\%)\end{array}$} & \multicolumn{3}{|c|}{ Univariate analyses } & \multicolumn{2}{|c|}{ Multivariate analyses } \\
\hline & & & & & & & $\chi^{2}$ & $P$-value & $\mathrm{HR}$ & $95 \% \mathrm{Cl}$ & $P$-value \\
\hline \multicolumn{12}{|c|}{ Pathological grading } \\
\hline Low & 21 & 6 & 30 & 5 & 5 & 0 & \multirow[t]{2}{*}{5.475} & \multirow[t]{2}{*}{0.019} & \multirow[t]{2}{*}{0.407} & & \\
\hline $\begin{array}{l}\text { Moderate or } \\
\text { high }\end{array}$ & 15 & 11 & 70 & 40 & 40 & 40 & & & & & \\
\hline \multicolumn{12}{|l|}{$\mathrm{D}_{90}$ (Gy) } \\
\hline$<110$ & 21 & 6 & 29 & 0 & 0 & 0 & \multirow[t]{2}{*}{5.465} & \multirow[t]{2}{*}{0.019} & \multirow[t]{2}{*}{2.395} & $1.507-$ & \multirow[t]{2}{*}{0.005} \\
\hline$\geq 110$ & 15 & 10 & 65 & 40 & 40 & 24 & & & & 9.872 & \\
\hline \multicolumn{12}{|c|}{ Lesion volume $\left(\mathrm{cm}^{3}\right)$} \\
\hline$<20$ & 11 & 11 & 76 & 46 & 46 & 46 & \multirow[t]{2}{*}{8.378} & \multirow[t]{2}{*}{0.004} & \multirow[t]{2}{*}{3.783} & & \\
\hline$\geq 20$ & 25 & 6 & 34 & 8 & 8 & 0 & & & & & \\
\hline \multicolumn{12}{|c|}{ Short-term efficacy } \\
\hline $\mathrm{CR}+\mathrm{PR}$ & 20 & 11 & 72 & 30 & 30 & 18 & \multirow[t]{2}{*}{19.348} & \multirow[t]{2}{*}{0.000} & \multirow[t]{2}{*}{0.203} & 0.479 & \multirow[t]{2}{*}{0.000} \\
\hline$S D+P D$ & 16 & 3 & 8 & 0 & 0 & 0 & & & & 0.340 & \\
\hline
\end{tabular}

$C l$ - confidence interval, $C R$ - complete response, $D_{90}-90 \%$ of target volume, HR - hazard ratio, KPS - Karnofsky performance status, PD - progress disease, $P R$ - partial response, $S D$ - stable disease, mo-months

A

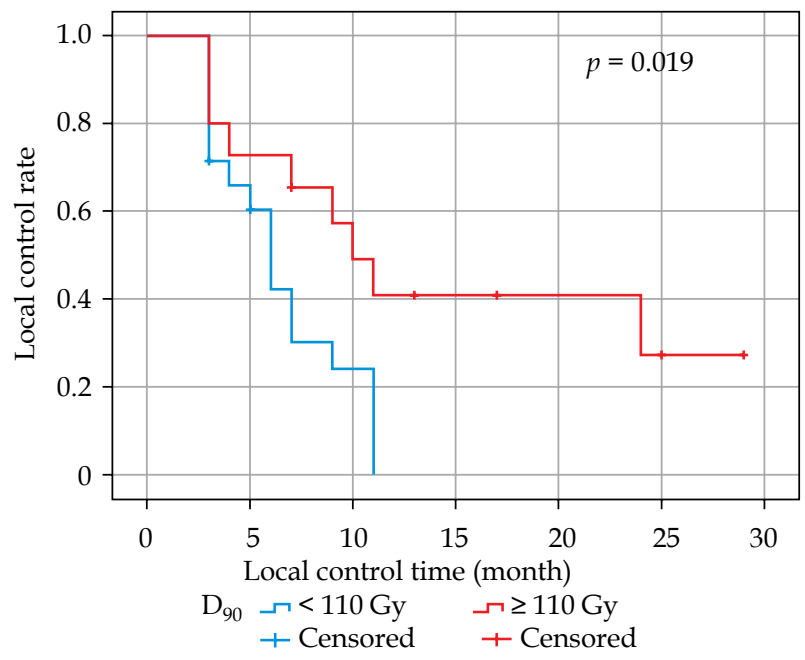

C

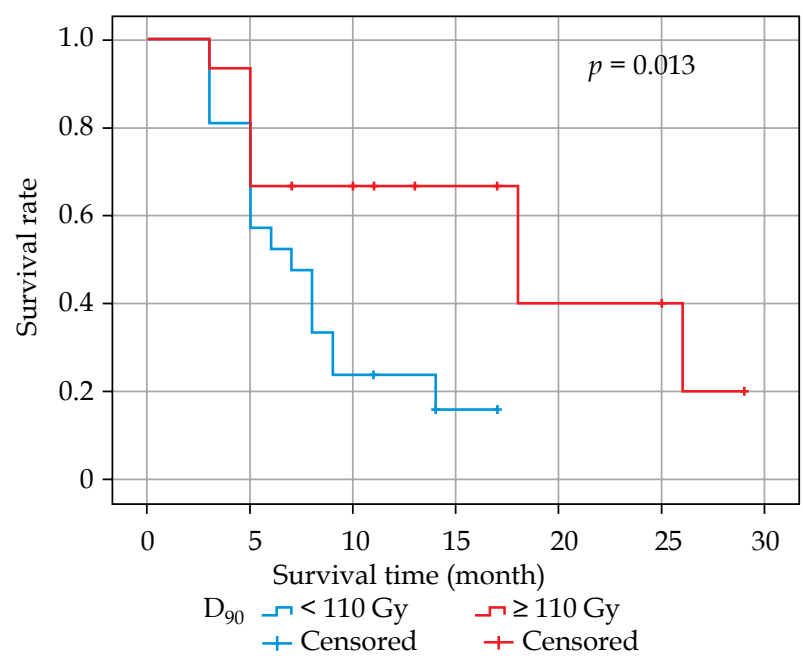

B

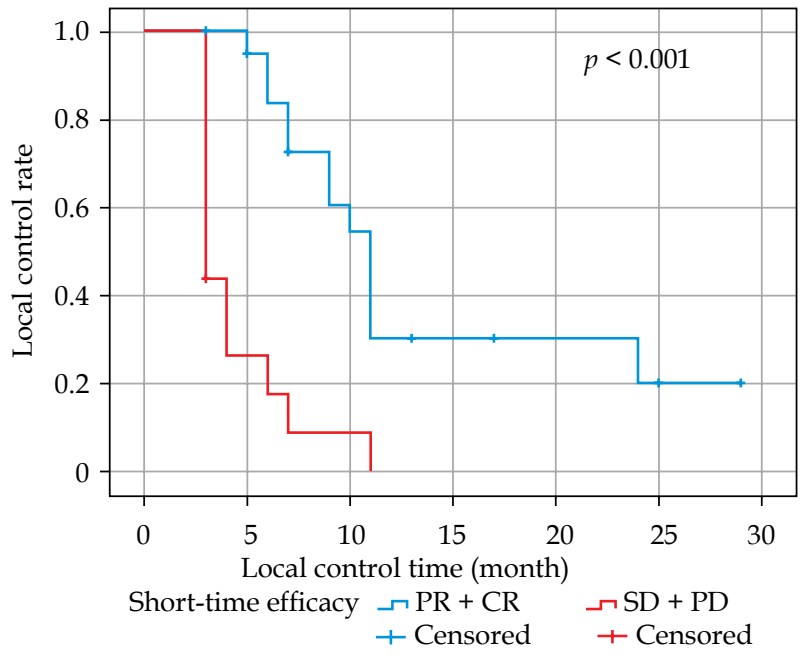

D

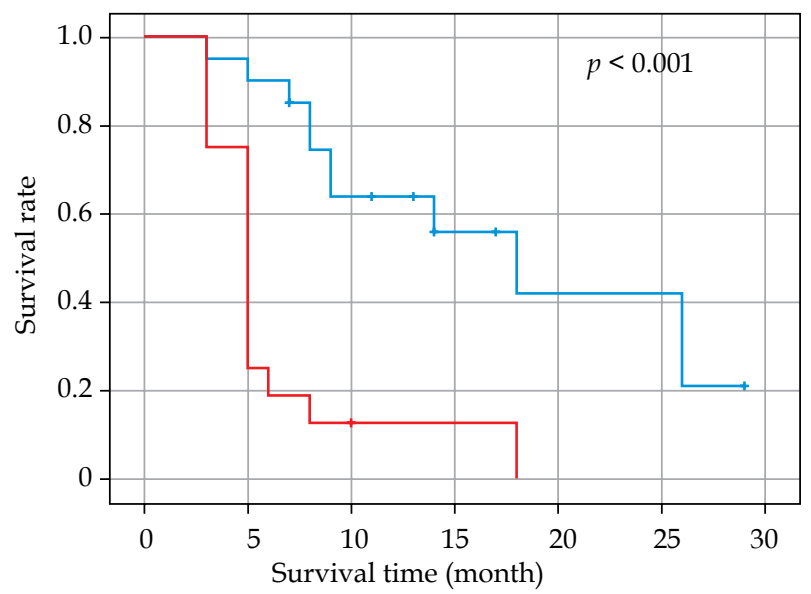

Short-time efficacy $\neg \mathrm{CR}+\mathrm{PR} \sim \mathrm{SD}+\mathrm{PD}$ + Censored + Censored

Fig. 2. Long-term local control rate and survival rate were higher for $D_{90} \geq 110 \mathrm{~Gy}$, with short-term efficacy reaching CR or PR 
3 cases $(8.3 \%)$ with grade 1 xerostomia. Lin et al. [19] showed that only one case $(1 / 19)$ had grade 4 skin toxicity. Therefore, it was confirmed by the above-mentioned studies that the radiation of ${ }^{125} \mathrm{I}$ seeds allows the adjacent normal tissue receiving sublethal or potentially lethal dose, and having sufficient time for repair [24]. No case reported post-operative bleeding. Intraoperative needle tract bleeding is more common. Surgeons should immediately insert the needle cores and use the tips to stop the bleeding without performing the operation for $1 \mathrm{~min}$. The surgeon should slowly retract $1 \mathrm{~mm}$ one or two times and observe, until the bleeding is stopped. An immediate compression for 10-20 min after surgery can effectively prevent post-operative bleeding [25].

In conclusion, our study found that radioactive ${ }^{125} \mathrm{I}$ seed implantation as a salvage treatment for patients with in-field CML-ESCC after radiotherapy showed definite efficacy and safety. When $\mathrm{D}_{90} \geq 110 \mathrm{~Gy}$ and the short-term efficacy reached CR or PR, the long-term local control and survival rate were significantly improved. However, this study was a single-center retrospective study, and the sample size of included patients was small. Meanwhile, slice thickness $5 \mathrm{~mm}$ in planning scan for seed brachytherapy may not be appropriate for every patient, especially for those with smaller tumor size. Therefore, the results of our research need to be confirmed by multi-center studies with a larger sample size.

\section{Conclusions}

Radioactive ${ }^{125}$ I seed implantation as an effective salvage treatment shows definite efficacy and safety for patients with in-field cervical lymph node recurrence of ESCC after external beam radiation therapy.

\section{Disclosure}

The authors report no conflict of interest.

\section{References}

1. Pennathur A, Gibson MK, Jobe BA et al. Oesophageal carcinoma. Lancet 2013; 381: 400-412.

2. Arnold M, Soerjomataram I, Ferlay J et al. Global incidence of oesophageal cancer by histological subtype in 2012. Gut 2015; 64: 381-387.

3. Chen W, Zheng R, Baade PD et al. Cancer statistics in China, 2015. CA Cancer I Clin 2016; 66: 115-132.

4. Allum WH, Stenning SP, Bancewicz J et al. Long-term results of a randomized trial of surgery with or without preoperative chemotherapy in esophageal cancer. J Clin Oncol 2009; 27: 5062-5067.

5. Juergens RA, Forastiere A. Combined modality therapy of esophageal cancer. J Natl Compr Canc Netw 2008; 6: 851-860.

6. Watanabe M, Nishida K, Kimura $Y$ et al. Salvage lymphadenectomy for cervical lymph node recurrence after esophagectomy for squamous cell carcinoma of the thoracic esophagus. Dis Esophagus 2012; 25: 62-66.

7. Nakagawa S, Kanda T, Kosugi $S$ et al. Recurrence pattern of squamous cell carcinoma of the thoracic esophagus after extended radical esophagectomy with three-field lymphadenectomy. J Am Coll Surg 2004; 198: 205-211.

8. Lee N, Chan K, Bekelman JE et al. Salvage re-irradiation for recurrent head and neck cancer. Int J Radiat Oncol Biol Phys 2007; 68: 731-740.
9. Bogaerts J, Ford R, Sargent D et al. Individual patient data analysis to assess modifications to the RECIST criteria. Eur J Cancer 2009; 45: 248-260.

10. Cox JD, Stetz J, Pajak TF. Toxicity criteria of the radiation therapy oncology group (RTOG) and the European Organization for Research and Treatment of Cancer (EORTC). Int J Radiat Oncol Biol Phys 1995; 31: 1341-1346.

11. Wang J, Yuan H, Ma Q et al. Interstitial 125 I seeds implantation to treat spinal metastatic and primary paraspinal malignancies. Med Oncol 2010; 27: 319-326.

12. Wang J, Jiang Y, Li J et al. Intraoperative ultrasound-guided iodine-125 seed implantation for unresectable pancreatic carcinoma. J Exp Clin Cancer Res 2009; 28: 88.

13. Zhang FJ, Wu PH, Zhao M. CT guided radioactive seed ${ }^{125} \mathrm{I}$ implantation in treatment of pancreatic cancer. Zhonghua Yi Xue Za Zhi 2006; 86: 223-227.

14. Chen Y, Jiang Y, Ji Z et al. Efficacy and safety of CT-guided 125I seed implantation as a salvage treatment for locally recurrent head and neck soft tissue sarcoma after surgery and external beam radiotherapy: A 12-year study at a single institution. Brachytherapy 2020; 19: 81-89.

15. Gao F, Li C, Gu Y et al. CT-guided ${ }^{125}$ I brachytherapy for mediastinal metastatic lymph nodes recurrence from esophageal carcinoma: Effectiveness and safety in 16 patients. Eur J Radiol 2013; 82: e70-75.

16. Wang J, Song ML, Zhang HT et al. Radioactive ${ }^{125} \mathrm{I}$ seed implantation for the treatment of recurrent cervical lymphatic metastases after radiotherapy: preliminary results in 17 cases. J Intervent Radiol 2014; 23: 784-787.

17. Park RI, Liberman FZ, Lee DJ et al. Iodine- 125 seed implantation as an adjunct to surgery in advanced recurrent squamous cell cancer of the head and neck. Laryngoscope 1991; 101: 405-410.

18. Chen KY, Mohr RM, Silverman CL. Interstitial Iodine 125 in advanced recurrent squamous cell carcinoma of the head and neck with follow-up evaluation of carotid artery by ultrasound. Ann Otol Rhinol Laryngol 1997; 105: 955-961.

19. Lin L, Wang J, Jiang $Y$ et al. Interstitial ${ }^{125}$ I seed implantation for cervical lymph node recurrence after multimodal treatment of thoracic esophageal squamous cell carcinoma. Technol Cancer Res Treat 2015; 14: 201-207.

20. Ji $Z$, Jiang $Y$, Tian $S$ et al. The effectiveness and prognostic factors of CT-guided radioactive $\mathrm{I}^{125}$ seed implantation for the treatment of recurrent head and neck cancer after external beam radiation therapy. Int J Radiat Oncol Biol Phys 2019; 103: 638-645.

21. Takiar V, Garden AS, Ma D et al. Reirradiation of head and neck cancers with intensity modulated radiation therapy: Outcomes and analyses. Int J Radiat Oncol Biol Phys 2016; 95: 1117-1131.

22. Spencer SA, Harris J, Wheeler RH et al. Final report of RTOG 9610, a multi-institutional trial of reirradiation and chemotherapy for unresectable recurrent squamous cell carcinoma of the head and neck. Head Neck 2010; 30: 281-288.

23. Langer CJ, Harris J, Horwitz EM et al. Phase II study of low-dose paclitaxel and cisplatin in combination with split-course concomitant twice-daily reirradiation in recurrent squamous cell carcinoma of the head and neck: results of Radiation Therapy Oncology Group Protocol 9911. J Clin Oncol 2007; 25: 4800-4805.

24. Zhang FJ, Li CX, Zhang L et al. Short- to mid-term evaluation of CT-guided 125I brachytherapy on intra-hepatic recurrent tumors and/or extra-hepatic metastases after liver transplantation for hepatocellular carcinoma. Cancer Biol Ther 2009; 8: 585-590.

25. Zhang $\mathrm{H}, \mathrm{Li} \mathrm{W}, \mathrm{Hu} \mathrm{Z}$ et al. Recommendations for $3 \mathrm{D}$ printing template to guide $125 \mathrm{I}$ radioactive seed implantation to treat esophageal cancer neck metastatic lymph nodes. Chin Med J 2018; 98: 3129-3133. 